

\section{A THEORY FOR INDIGENOUS AUSTRALIAN HEALTH AND HUMAN SERVICE WORK}




\section{A THEORY FOR \\ INDIGENOUS \\ AUSTRALIAN HEALTH \\ AND \\ HUMAN SERVICE WORK}

Connecting Indigenous knowledge and practice

\section{LORRAINE MULLER}

Foreword by Professor Boni Robertson

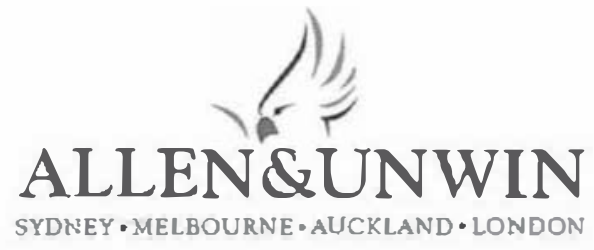


Lorraine Muller is a Murri woman with many years experience in community work. She holds a PhD in Social Work, and is an Adjunct Senior Research Fellow in the School of Medicine and Dentistry at James Cook University, where she is currently undertaking her second $\mathrm{PhD}$. 
First published by Allen \& Unwin in 2014

Copyright @ Lorraine Muller 2014

All rights reserved. No part of this book may be reproduced or transmitted in any form or by any means, electronic or mechanical, including photocopying, recording or by any inf ormation storage and retrieval system, without prior permission in writing from the publisher. The Australian Copyright Act 1968 (the Act) allows a maximum of one chapter or 10 per cent of this book, whichever is the greater, to be photocopied by any educational institution for its educational purposes provided that the educational institution (or body that administers it) has given a remuneration notice to Copyright Agency (Australia) under the Act.

Allen \& Unwin

83 Alexander Street

Crows Nest NSW 2065

Australia

Phone: (612) 84250100

Email: info@allenandunwin.com

Web: www.allenandunwin.com

Cataloguing-in-Publication details are available

from the National Library of Australia

www.trove.nla.gov.au

ISBN 9781743317198

Internal text design by Alissa Dinallo

Typeset in 11/16pt Minion by Post Pre-press Group, Australia

Printed and bound in China by Hang Tai Printing Company Limited

10988765543321 


\section{ONTENTS}






\section{F O R E W O R D}

I was deeply honoured and humbled when invited to write the foreword for Lorraine Muller's book, A Theory for Indigenous Australian Health and Human Service Work. At a time when the development of a more astute interactional framework around the engagement of nonIndigenous professionals with Aboriginal and Torres Strait Islander Australians is generating a lot of interest, this book provides a much overdue and timely response.

Lorraine Muller utilises her cultural and professional experiences to provide the reader with an analysis and articulation of issues that impact upon Indigenous Australians within the context of Australia's health and human services. From the outset, the author fills the reader with a sense of enquiry as she cleverly adopts both a professional and cultural lens to explore an ideological and theoretical overview of social science and social work, which she aptly names 'social health'. This analysis provides a unique challenge to stereotypic meanderings of ten expressed about Indigenous Australians in the workplace and puts paid to archaic notions of Indigenous contributions to the Australian social, economic and political landscape.

The author takes the reader on a personal and intellectual journey of conf rontation, cultural ignorance and reform as she reveals her own experiences within the academy when confronted by non-Indigenous supervisors who were, too often, culturally inept. In highlighting this anomaly Muller states that 'While it was recognised that Indigenous Australians have a different way of working, as documented in Murri Way!, a "different way of working" is of ten relegated by non-Indigenous supervisors, co-workers or employers to a "welfare context" in the workplace, creating for the Indigenous worker a whole scenario of stereotypes to contend with.'

At a point when 'closing the gap' on Indigenous poverty has been embraced as a national policy by all levels of government, the need for 
a more concise and culturally apt assessment of social policy practices and processes for Indigenous Australians is urgently required. Muller's work provides a critical framework that will stand as an influential guide for governments, child protection and allied professions in health, education, social justice and human rights, whose mandate is to develop and deliver social policy and services for Indigenous Australians.

The author has provided a review of historical and contemporary sources pertinent to child protection, the progression of selfdetermination and the development of sociai policy for Indigenous Australians. This presents for the reader a comprehensive framework around extremely controversial and culturally sensitive social and political issues, which have emerged in the wake of the Northern Territory Intervention and welfare reform. This book provides an opportunity for a new dialogue to take place around the development and implementation of social policy and service delivery regarding Indigenous Australians.

I consider this book to be unique in a number of ways. Most importantly, its uniqueness rests in the ability of the author to transcend the inability of many Indigenous Australians to articulate their experiences within the workplace or within education systems for fear of being labelled antagonistic or stereotyped. Muller has provided an uncompromising account of her personal and professional experiences of racism, segregation and isolation as a student and, subsequently, in the workplace. I believe her courage will prove to be enlightening to many readers, especially those committed to progressing the rights of Indigenous Australians and those who seek more proactive ways in which to understand and address the ongoing disadvantage of Indigenous communities.

While the book profiles the personal and professional journey of the author within a social work and human service framework, the issues raised will strike at the heart of many Indigenous and nonIndigenous Australians interested in social justice and the principles 
of social inclusion, cultural respect and professional competency when working with Indigenous communities. Throughout the text the author skilf ully and sensitively discusses the issue of Indigenous resilience and determination, and profiles the scholarship of Indigenous knowledge and philosophical world views, enunciating the critical role that these play in addressing the wellbeing and self-determination of Indigenous Australians.

Muller discusses issues of spirituality, tradition, culture, obligation and reciprocity from her own cultural perspective within a Western professional environment. She provides a crucial insight into these areas with dignity and respect for her own Indigenous heritage and for the non-Indigenous reader, who may seek to be enlightened on such issues.

This book will prove to be a powerf ul educational tool and workplace resource. The author's use of critical discourse as a means of analysing and understanding the interaction and cultural nuances between Indigenous and non-Indigenous players within her field of study provides a new understanding of issues that for many Indigenous Australians has become an ongoing and serious matter of concern.

Anyone interested in human rights, social interaction and the development of social policy and practices that are symbolic of the true needs of Indigenous Australians will gain immense insight from reading this book. For many, reading this book may be cathartic, for others it may be confronting, but for all readers it will present a compelling inside account of what it is like to be an Indigenous Australian within the workplace, as a recipient of services or within society in general.

Professor Boni Robertson PhD Director, Office of Indigenous Community Engagement, Policy and Partnerships 


\section{A C K N OW LEDGEM E N'TS}

I am privileged to have been given the opportunity and trust to undertake this research. I am respectful of the responsibility to knowledge that has been entrusted to me.

I would like to acknowledge and express my gratitude to the many people who have helped me in this research:

I acknowledge Elders past, Elders present and Elders of the future.

I thank the people who have given me support, encouragement, guidance and who have shared their knowledge so generously with me, from the beginning to the end of this project.

In particular I want to acknowledge the people who approached me during the course of this research, giving me specific knowledge they wanted included.

Professor Boni Robertson honours me by writing the foreword of my book. Boni was intentionally not part of the expert panel and the general research as she is the most prominent expert in this field and I so desperately wanted her as a marker of my thesis. Boni's work has provided great inspiration to me throughout my research and I can think of no one more eminent to introduce this publication. Thank you, Boni.

I am humbled by the support of the people who collectively make up the 'expert panel', who checked the thesis for content to ensure the 
validity of the knowledge shared in this project and that it is culturally appropriate to share. Their commitment has been unwavering. I thank the expert panel for this support.

I would like to give my special thanks to the members of the expert panel: Tom Calma, Mick Adams, Jody Saxton, Gracelyn Smallwood, Dorothy Savage, Angela Clarke, Stephen Corporal, Randal Ross, Tammie Harrison, Phillip Rist, Mark Wenitong, Debra Hunter-McCormick, Lyndon Reilly, Paul Pedro, Susan Klein, Roxanne Bainbridge, Roslyn Von Senden, Vicki Saunders, Yvonne Cadet-James, Steven Larkin, Ian Anderson, Johnathan Link, Priscilla Page, Nancy Bates, Larraine Gabey, Elizabeth Trindle, Kathleen Johns, Senimelia Kingsburra, Lisa Curtis, Felicia Fletcher, Tileah Drahm-Butler, Patsi Mawn, Patricia Johnson, lane Locke, Debra Bennet, Lyn Hughes, Diane Choikee, Mick Gooda. I am honoured to have had the opportunity to learn from their knowledge.

I thank Dr Susan Gair and Professor Ros Thorpe. I appreciate their assistance in helping me gain further understanding about non-Indigenous culture. Thank you both for your friendship and for sharing your wisdom.

Of special note, I would like to acknowledge and express my appreciation to my friend Mrs Kath Hinchley. Kath tutored me in academic writing and grammar, proofreading my work throughout my undergraduate and post-graduate studies. I am fortunate to have a friend like Kath.

Elizabeth Weiss and her colleagues at Allen \& Unwin have my gratitude for their guidance and faith in the value of taking this shared knowledge into this publication.

To my husband, Rob, my children and my grandchildren, I owe special thanks for their unwavering support. 




\section{Chapter 1}

\section{THE POWER OF STORY}

I always knew that I was a little bit different, not black enough to be black, and not white enough to be white- I am not quite white.

Indigenous writers and speakers normally introduce themselves by saying what Country and peoples they come from because this is the basis of their identity. Like many others, 1 am not able to introduce myself and my connection to Country. My connection to Country and kin was denied due to the colonisers' policies and I mourn the loss of connection. In spite of the social engineering policies to 'breed out the colour' that denied me that right, it was clear to me that I had a way of looking at the world that did not fit within the conventional social script.

I was bom on Kalkadoon Country (in North Westem Queensland), raised in Zenadh Kes (the Torres Strait) and live on Girramay Country (Cardwell, North Queensland). It was not until my late 30 s, when I finally got to university, that I realised how different I was from the mainstream. I was a mother of four, with the youngest close to finishing high school. Having worked as a coordinator in the Aboriginal Tutorial Assistance Scheme's homework program, working with mostly non-Indigenous teachers and Indigenous parents and children, I had thought that I was reasonably literate in the mainstream discourse. My experiences with mainstream education systems, while my children were at school, should have alerted me to some of the difficulties I was to face in my own studies. To give an example of this different world view, during preparations at the local primary school for NAIDOC celebrations (a week of celebration of Aboriginal and Torres Strait Islander cultures named after the National Aboriginal and Islander Day Observance Committee), the principal could not see a disparity when he expected Elders to share their cultural knowledge on a voluntary basis, including providing their own transport, while he was being well paid for passing on his settler culture.

It was a shock when 1 began studying in the social sciences and I was confronted with a world view and cultural truths that clashed with my understanding of the world. Acceptance of the legitimacy of the colonialist interpretation of history and reality challenged me. I reject the use of 'we' to mean 'white/dominant class'. I struggled, and continue to struggle, to understand how a concept such as patriarchy is understood to be a 'truth' to be challenged by feminist theory, when 1 know it as a pestilent concept that was introduced with occupation. Theories and practice models in the social sciences appeared to me to be distorted by foreign cultural assumptions and values.

While I was negotiating my way through this alien landscape of knowledge, I found Indigenous Australian writers reflected my understanding of knowledge and truths. I questioned the reliance on Western theory in tertiary education. The Aboriginal and 
Torres Strait Islander Women's Task Force on Violence Report, chaired by Boni Robertson, became my inspiration and my most treasured textbook, for it contained a historical and theoretical base that I could relate to (Robertson, 2000). Indigenous writers discussed theories of relatedness and acceptance of our spirituality that resonated within me (Atkinson, 2002; Martin, 2003; Robertson, 2000).

While this realisation has been a personal pilgrimage for me, these studies have raised my consciousness of the void in literature on theories that relate to the context, values, history and spirituality of Indigenous social-health and welfare practice. Rather than feeling confident in my knowledge after successfully completing mainstream studies, graduating in social science and social work with honours degrees, I remained unfulfilled -something was missing. I knew there is a way of working not represented in the mainstream curriculum: knowledge that has been subjugated.

It was during the latter part of my undergraduate studies that this research project found me. It has been recognised that Indigenous Australians have a different way of working, as documented in Murri Way! ('Murri' refers to Aboriginal and Torres Strait Islander Queenslanders; it can sometimes be taken as an offensive term); however, this different way of working was often relegated to that of the 'other' in welfare texts (Lynn, Thorpe, Miles, Cutts, Ford \& Butcher, 1998). The topic became obvious following discussions in 2003 with my fellow social-work students, Robyn and Paul, about the difficulties of trying to negotiate the relevance of theories and practices that were centred on values and a world view that were foreign. It was clear to us that there is a metatheory informing practice of Indigenous people in the helping professions. Our discussions revealed that we knew many students who, if our theory and praxis were available, would be more likely to relate to and succeed at tertiary studies.

Tokenism and racism are evident in many forms in modem Australia, particularly in the helping professions, and addressing these issues was a major impetus for my research. The majority of people who shared their knowledge with me discussed incidents where their knowledge had been sought and then disregarded or ridiculed. To be the 'token blackfella' is an occupational issue that causes real stress to workers. Although tokenism and racism are not the focus of my research, they were themes that arose in almost all of my conversations, and it is hoped that by documenting our knowledge these issues can be challenged.

Conversations with people working in the Indigenous social-health services confirmed for me that the absence of formal and accessible Indigenous theory within the education sector was an enormous barrier to participation. 'Social health' is a term I use that takes its place alongside, and at times incorporates, the terms 'mental health' and 'physical health', to form the holistic notion of 'social and emotional wellbeing' (Purdie, Dudgeon \& Walker, 2010, p. xxvi). I use the term 'social health' as it reflects a holistic model of practice that incorporates the many disciplines where the social, emotional (including spiritual) and physical health of our people is central to practice.

My goal in my research was to identify what is unique about Indigenous Australian social-health theory and practice. This book is an example of Indigenous social-health theory in action. Honouring our ways of working, this book has a circular structure. Starting with foundational knowledge, 1 return in later chapters to points raised in the earlier chapters, positioning the reader with the necessary knowledge to take deeper learning at each encounter. Rather than just me writing about it, readers get a chance to experience this circular way of learning.

Respecting that a person can only speak for themselves, unless explicit permission is given, I break with Western academic protocols and weave my own story into my work.

As an Indigenous Australian woman I am acutely aware that this task brings with it enormous responsibility. My personal integrity will be scrutinised and I will be held accountable for the validity of the project. Although I am the researcher in this project, my own knowledge, thinking and interaction with the learning process are indelibly part of the research, for this is insider research (Tuhiwai-Smith, 1999). Through the pilgrimage of this research, I have been fortunate to learn from many people who shared their wisdom and knowledge so generously. It has also been a challenging journey. At times, the 